\title{
Knowledge, attitudes, and practices of responsive feeding in rural Sri Lanka (A qualitative study)
}

\author{
P Pallewaththa ${ }^{1}$, S B Agampodi ${ }^{1}$, T C Agampodi ${ }^{1}$, S H Siribaddana ${ }^{1}$ \\ (Index words: child nutrition, child health, complementary feeding, responsive feeding, under nutrition)
}

\begin{abstract}
Introduction Responsive feeding has been proven to be an effective feeding method for children who are at early stages of development. The concept is not popular at the primary health care level and it is reported as a missing link in the current nutrition program in Sri Lanka.

Objective To explore responsive feeding practices among caregivers who have an infant aged between 6 to 12 months and residing in rural Anuradhapura.

Methods A qualitative approach was adopted. The study was carried out in Padaviya Medical Officer of Health area. Study participants were 18 mothers and all ten Public Health Midwives. Diary studies, interviews and focus group discussion were conducted to collect data. The framework approach was used to analyze the data.

Results Pleasant and healthy feeding environment is non-existent. Identification of hunger and satiety cues was poor and hunger sensitive schedule to feed the child was absent. Feeding situations commenced in an emotionally supportive manner, but were not optimally utilized to promote psycho-social stimulation. During the feeding caregivers neglect emotional support and ultimately moves to forceful feeding.
\end{abstract}

Conclusions The knowledge, attitude and practices are poor on responsive feeding among caregivers and health workers. This may contribute to poor growth and development in children. Action is needed to implement RF practices in the community.

Ceylon Medical Journal 2019; 64: 70-75

DOI: http://doi.org/10.4038/cmj.v64i2.8894

\section{Introduction}

Nutrition during the early years of life is crucial for healthy adulthood. Globally, approximately 151 million children are stunted and more than half of them are from Asia [1]. Even though Sri Lanka achieved many milestone related to maternal and child health, nutrition is still a major public health issue. Prevalence of underweight children (weight-for-age $\leq-2 \mathrm{SD}$ ) aged 0-1, 1-2 and 3-5 years in Sri Lanka was 6.5\%, 14.3\% and 21.2\% in 2016 [2].

Inappropriate feeding practices are considered a major factor in childhood under-nutrition in developing countries $[3,4,5,6]$ and the same was observed in Sri Lanka [7]. The general decline in growth with the introduction of complementary feeding is attributed to many factors including responsive feeding [8]. Responsive Feeding (RF) emerged from a study in mid-1990 in Nicaragua [9]. A systematic review has shown the positive effects of the RF on the child's food intake [10]. In terms of behaviors, there is an association between positive behavior of the caregiver and acceptance of food by the child [11].

RF includes three components [12].

1. Ensuring that the feeding context is pleasant with few distractions; that the child is seated comfortably, ideally facing others; that expectations are communicated clearly; and that the food is healthy, tasty, developmentally appropriate, and offered on a predictable schedule so the child is likely to be hungry

2. Encouraging and attending to the child's signals of hunger and satiety

3. Responding to the child in a prompt, emotionally supportive, contingent, and developmentally appropriate manner.

$\mathrm{RF}$ is listed as the fifth component in Sri Lankan Infant and Young Child Feeding (IYCF) guidelines. However, many primary health care workers are unaware of it making RF the missing link in the current nutrition program [13]. Previous studies showed the knowledge on the RF among mothers as well as Public Health Midwives (PHM) are inadequate [14,15]. Sri Lankan study showed the RF practices improve eating behaviors and child growth [16]. However, studies based on concepts of the RF are absent in Sri Lanka. The objective was to explore knowledge,

${ }^{1}$ Faculty of Medicine and Allied Sciences, Rajarata University of Sri Lanka.

Correspondence: PP, e-mail: <vpvijihp@gmail.com>. Received 6 December 2018, revised version received 13 May 2019 and accepted 16 June 2019.

This is an open-access article distributed under the terms of the Creative Commons Attribution License, which permits unrestricted use, distribution, and reproduction in any medium, provided the original author and source are credited. 
attitudes and practices of the RF among caregivers residing in rural Anuradhapura.

\section{Methods}

A qualitative approach was adopted to explore knowledge, attitudes and practices on RF. It included diaries about feeding practices and diary based in-depth interviews with mothers. After, Focus Group Discussion (FGD) was held with PHM. The study was carried out in Padaviya Medical Officer of Health $(\mathrm{MOH})$ area, Anuradhapura district. It has a population of 27,535, (predominantly Sinhalese) residing in an area of $235 \mathrm{~km}^{2}$. There are 10 PHM divisions and in 2013 approximately $20 \%$ of under five children were underweight [17]. Through informal discussions we identified three distinct communities residing in the area.

1. Early settlers (1950s and 1960s) in semi-urban areas

2. New settlers before and during internal armed conflict (since 1970s onwards) in rural areas

3. Recent settlers after internal armed conflict (after 2009 May) in rural areas

Padaviya, Abhayapura (early settlers), Parakramapura (new settlers) and Buddhangala (recent settlers) PHM areas were selected for the diary study. Purposive sampling was done to select participants, based on literacy.

A mother (in the selected PHM area) of an infant between 6 to 12 months without an illness that can affect feeding was defined a study participant. All ten PHMs were invited for the FGD. Interviews were conducted till data saturation.

Diary based qualitative research were previously carried out in this area [18]. Optimal duration of a solicited diary is two weeks [19]. Main items included are time, type of food, feeding environment, identification of signals of hunger and satiety, and behavior of the mother after satiety. Printed diaries were given after obtaining the written informed consent. The Principal Investigator (PI) met each mother individually and explained the importance of documentation and encouraged to report her natural behavior during the feeding time. Model diary and separate written instructions on how to complete was also given. PI visited the participants after a week and during the second week to motivate. The PI identified items that needed further clarifications from the diaries, and included them in the interviewer guide (Annex 1). The interviews were conducted within one month after completion of the diaries, at the weighing clinics. FGD was conducted according to the Family Health International (FHI) guidelines [20]. The moderator led and recorded the FGD and a trained assistant took notes. Notes were expanded immediately typed and attached to the transcript. In addition, awareness and attitudes among PHMs, and application of RF by mothers were also included in the guide to FGD (Annex 2).
The frame work approach was used to analyze the data. Triangulation by face-to-face interviews and FGD was carried out. Respondent validation method was used to increase the validity of FGD. The study tools were pilot tested. The PI and an external analyzer independently analyzed the data and differences resolved with discussion.

Ethical clearance (ERC number: ERC/2014/060) was obtained from the Ethics Review Committee of the Faculty of Medicine and Allied Sciences of the Rajarata University of Sri Lanka.

\section{Results}

Eighteen mothers (20-42 years) and 10 PHMs (31-41 years) were studied. Three mothers (16.7\%) were employed. One mother has completed primary education and all others have studied more. All mothers filled the diary and were interviewed.

\section{$R F$ practices among caregivers}

1. Feeding environment was unpleasant, only two have a separate place to eat and others were fed at multiple sites using distraction. Environment was not optimally utilized to promote psychosocial stimulation.

2. Identification of hunger cues (fussing, crying and gnawing on hands or fingers) was poor. Shaking head from side to side, swiping away the food and turning away from the spoon were the satiety cues. Hunger sensitive schedule to feed was absent.

3. Feeding commenced in an emotionally supportive manner but with time, forceful feeding was observed. Self-feeding was neglected (Table 1).

\section{Knowledge about RF among mothers and PHMs}

Only three had heard about RF (15/18 - 84\% have not heard) and could not recall the source of information. They were not aware about the three components and benefits of the RF and only heard about the term. However, mothers were aware that feeding behavior as an important component. In FGD, PHM too said that mothers' awareness was poor. Knowledge on three components and benefits of the RF is poor among PHMs too. PHMs understanding were that 'RF was feeding the child without forcing'.

\section{Attitudes about RF among mothers and PHMs}

Health education on complimentary feeding programs was conducted by PHMs but no such programs were conducted on RF. Mothers were dissatisfied with lack of instructions on RF by PHMs. Attention has been paid mainly on quantity, quality and the diversity of food (Table 2). 
Table 1. Summary of the results in RF practices among mothers

RF Step (12)

Responses (I- interview, $D=$ diary)

\section{Step one; Proactive preparation}

Sub themes; pleasant and non-distractive environment, child sitting comfortably facing others, expectations communicated clearly, healthy, tasty and developmentally appropriate food, feeding time according to the child's hunger cues.
Step two: Identification of signals of hunger and satiety

Sub themes; hunger and satiety cues.

\section{Step three: Responding to the child}

Sub themes; promptly in an emotionally supportive, contingent manner, developmentally appropriate feeding (allow child for self-feeding).
"Child was given food, while walking (D-1)". Most of the time, I feed while he plays, he has a play cart. He was fed while he was playing with it (I-4).

Child doesn't sit down to eat. The child was fed, while walking; dancing; playing with pets; showing the environment; keeping the child on a vehicle; watching TV or listening to radio. Therefore, the feeding environment was distractive.

"It is difficult to feed in a separate place. I have to go to different place"(D-10). "Child was given food, while showing birds, squirrels, and flowers. He had two, three mouthfuls while looking" (D-1). "Mothers are running around to feed the child (FGD)".

Mothers listed each meal. Health and tasty meals were prepared. "Prepare meal with more milk" (D-5). Food was diverse and when needed extra meals were prepared. Some adjusted the feeding schedule for their own convenience ignoring the child's hunger. Mothers offered meals, before or after bathing the baby or before the baby slept.

"Younger child was fed while preparing elder child to the pre-school”(D-5). “Child was playing” (D-2).

"Normally, the child's breakfast is between 8 a.m. and 9 a.m.” (D-7).

"Normally, I feed the child after giving bath" (DP-10).

"I endeavor to offer two meals per day" (D-15).

"Most of the time mothers feed children, when child do not show any desire to eat (FGD).

"If I offered another bite, he throws up" (I-6). "When I offer a bite he hits my hand” (D-9).

Mothers tell stories, clap, and sing songs. Most of the time forceful feeding was observed as fear is aroused to feed the child. "Mothers force food to the child (FGD).

"Practically, mothers gradually changed their behavior to feed children, adapting to schedules in the Growth Record Book" (FGD). "At the beginning he ate well, but when few more bites were offered he started to reject ... finally I started to feed forcefully" (I-1). 
Table 2. Summary of the results in attitudes on RF among mothers and PHMs

Mothers' opinion (MO) on feeding behavior for child growth and development.

MO on health education programs on RF conducted by PHMs.

MO on quality and quantity of the meals

PHMs’ opinion on current nutrition programs

PHMs' opinion on RF.

PHMs’ opinion on public awareness on RF
"Child is unhappy, when trying to feed forcefully. So feeding behavior is important"(I-10)

"No awareness programs about responsive feeding" (I-3). "PHM told us to start complementary feeding by six months. . but they did not mention about RF” (I-8)

"Quality, quantity and feeding behavior are important to child growth” (I- 12).

"We are conducting our programs well. But RF is a missing part” (FGD).

There are no programs to promote RF. However they introduced group feeding and playhouse as a feeding place. "We educate them. Then they implement" (FGD). "The child is given food in a playhouse. "Group feeding was introduced at the weighing post” (FGD).

PHMS stated mothers' awareness on RF is poor.

"Initially mothers follow instructions on complementary feeding later they do not” (FGD). "We educate them"(FGD).

\section{Discussion}

This study is on complementary feeding behaviors of caregivers of infants using qualitative techniques. The knowledge was insufficient, attitudes were poor, and the practices were sub-optimal among caregivers in the study area. The primary healthcare workers and mothers have less insight towards the concepts of the RF and its importance. RF is included in the feeding guidelines, and commitment of families and health care workers is advocated but not implemented [21].

A calm comfortable setting for feeding is an important element in RF [22]. Taking the child from place to place and using distraction to feed is not seen as harmful and the practices are deeply rooted. PHMs do not have capacity to formulate effective counter measures for this behavior. We find this as a major drawback to implement the RF. Gathering children away from home to a common place to promote group feeding was observed and may be convenient for caregivers, but it is distractive and against the concept of the RF.

Caregiver's ability to identify hunger and satiety cues is central to the RF $[13,23]$. Although mothers knew about hunger and satiety cues, schedule for feeding was not based on signals from the child. Caregiver's capacity needs to be enhanced to schedule mealtimes based on infants hunger cues. Changing behaviors need more than the routine nutritional programs [24]. Although had heard the term, "feeding the child according to his or her desire" mothers are unaware and less confident about the concepts of RF. Unlike other health promotion concepts delivered by PHMs the RF was not conveyed to mothers. A wholesome approach with strategies to change the behavior needs at the center and community. Nonresponsive feeding practices [23] such as forceful feeding was observed. Another detrimental practice was arousing fear in the child. Feeding commenced in an emotionally supportive manner, but was not optimally utilized to promote psychosocial stimulation. Caregivers overlook offering emotional support and at the end, forceful feeding was observed.

Inadequate evidence about the RF in Sri Lanka may be a reason for limited attention on RF by policy makers. Dialogue generated at local nutrition forums do not focus on the behavioral change. As malnutrition is one of the largest risk factors for mortality of young children, appropriate child feeding practices and behaviours of parents have a positive effect on child growth. The National Nutritional Policy is to achieve and maintain the nutritional wellbeing, and to reduce malnutrition [25]. Childhood malnutrition is a public health challenge and the RF is a missing component in the infant and child feeding 
protocols of developing countries. Inclusion of children aged 6-12 months in this study represent a limited age span, and it is acknowledged that feeding interactions may differ substantially as the child grow older [26]. The multi-faceted approach (diary, interviews and focus groups) was strength and three key areas of RF could be examined: knowledge, attitudes, and practices. Gender was not emphasized among the selected caregivers; not only mothers, fathers, grandparents and others as caregivers influence the RF practices. Self-reported data are prone to response bias. Specially, research is needed for understanding efficacy of RF interventions to promote child growth and development in Sri Lanka. Developing methods to assess the RF practices should be a priority. In addition, health promotion interventions to promote RF practices are essential. This study provides the basis for future studies to formulate an instrument for measuring RF practices.

\section{Conclusion}

Knowledge, attitudes and practices are poor on RF among caregivers and health workers. This may contribute to poor growth and development in children and action is needed to implement RF practices in the community.

\section{Acknowledgements}

Participants of the study and PHMs in Padawiya $\mathrm{MOH}$ area, the Regional Director of Health Services, Anuradhapura are acknowledged.

\section{Conflict of interests}

All authors have reviewed and approved the final manuscript and we have no conflict of interests.

\section{References}

1. UNICEF, WHO, World Bank. Levels and trends in child malnutrition. Geneva: WHO, 2018.

2. Family Health Bureau. Statistics. Available from: http:// www.fhb.health.gov.lk/index.php/en/statistics. (accessed on April 25, 2019).

3. Zhao A, Gao H, Li B, et al. Inappropriate feeding behavior: one of the important causes of malnutrition in 6 to 36 month old children in Myanmar. Am J Trop Med Hyg 2016; 95(3): 702-8.

4. Lamichhane DK, Leem JH, Kim HC, et al. Association of infant and young child feeding practices with undernutrition: evidence from the Nepal Demographic and Health Survey. Paediatr Int Child Health 2016; 36(4): 260-9.

5. Zongrone A, Winskell K, Menon P. Infant and young child feeding practices and child under nutrition in Bangladesh: insights from nationally representative data. Public Health Nutr 2012; 15(9): 1697-704.
6. Yabanci N, Kisac I, Karakus SS. The effects of mother's nutritional knowledge on attitudes and behaviors of children about nutrition. Procedia Soc Behav Sci 2014; 116: $4477-81$.

7. UNICEF, Ministry of Health. Combating Malnutrition through multisectoral nutrition programming: A Case Study from Sri Lanka. Colombo: Ministry of Health, 2015.

8. Ministry of Health, UNICEF. Sri Lanka Complementary feeding study - Factors associated with complementary feeding in Sri Lanka. Colombo: Ministry of Health, 2008.

9. Engle PL, Zeitlin M. Active feeding behavior compensates for low interest in food among young Nicaraguan children. J Nutr 1996; 126: 1808-16.

10. Bentley ME, Wasser HM, Creed-Kanashiro HM. Responsive feeding and child under nutrition in low- and middle-income countries. J Nutr 2011; 141(3): 502-7.

11. Ha PB, Bentley ME, Pachon H, et al. Caregiver styles of feeding and child acceptance of food in rural Vietnam. Food Nutr Bull 2002; 23 Suppl 4: 95-100.

12. Black MM, Aboud FE. Responsive feeding is embedded in a theoretical framework of responsive parenting. J Nutr 2011; 141(3): 490-4.

13. Agampodi TC. Responsive feeding: the missing link in child malnutrition in Sri Lanka. Sri Lanka Journal of Child Health 2014; 43(1): 53-4.

14. Senevirathne SS, Karunamuni N, Pallewaththa PW, et al. Responsive feeding practices among caregivers in rural Anuradhapura; a missing component in infant feeding. Anuradhapura Medical Journal 2015; 9 Suppl 2: S04.

15. Karunamuni N, Senevirathne S, Pallewaththa PW, et al. Knowledge and perceptions on responsive feeding among primary health care providers at field level in rural Anuradhapura. Anuradhapura Medical Journal 2015; 9 Suppl 2: S08.

16. Jayawickrama HS. Impact of responsive feeding on feeding behavior and growth of young children. Colombo: University of Colombo, 2006.

17. Medical Officer of Health Office Padawiya, H512 Quarterly report, Padawiya: Medical Officer of Health Office Padawiya, 2013.

18. Agampodi TC, Rheinlander T, Agampodi SB, Glozier N, Siribaddana S. Social capital and health during pregnancy; an in-depth exploration from rural Sri Lanka. Reprod Health 2017; 14: 89.

19. Jacelon CS, Imperio K. Participant Diaries as a Source of Data in Resource with Older Adults. Qual Health Res 2005; 15(7): 991-7.

20. Family Health International. Qualitative Research Methods; A Data Collectors' Field Guide. North Carolina: Family Health International, 2011.

21. Silva GA, Costa KA, Giugliani ER. Infant feeding: beyond the nutritional aspects. J Pediatr (Rio J) 2016; 92(3): S2-7. 
22. Almaatani DE, Mann L, Kelly E, Rossiter M. Responsive Feeding Practices and Influences: A Qualitative Analysis of Parent Experiences with Feeding their Young Children. Am Int J Contemp Res 2017; 7(2): 56-65.

23. Harbron J, Booley S, Najaar B, Day CE. Responsive feeding: establishing healthy eating behavior early on in life. South Afr J Clin Nutr 2013; 26(3): 141-9.

24. Kanashiro HC, Bartolini R. Responsive feeding in Peru: Application and monitoring of an intervention among families with small children from an area of the Ucayali region. Available from: https://www.k4health.org/sites/ default/files/Final\%20report\%20Responsive\%20feeding \%20020509.pdf. (accessed on Sep 03, 2017).

25. Ministry of Health Care and Nutrition, National Nutrition Policy, Colombo: Ministry of Health Care and Nutrition, 2010.

26. Finnane JM, Jansen E, Mallan KM, Daniels LA. Mealtime Structure and Responsive Feeding Practices Are Associated With Less Food Fussiness and More Food Enjoyment in Children. J Nutr Educ Behav 2016; 49(1): 11-18. 